Editorial

\title{
Introduction to "Indicators and Measurement of Social Inclusion"
}

\author{
Peter Huxley \\ School of Social Sciences, Bangor University, Bangor, LL57 2DG, UK; E-Mail: p.huxley@bangor.ac.uk
}

Submitted: 14 July 2015 | Published: 24 July 2015

\begin{abstract}
The papers in the special issue cover some of the most significant methodological and conceptual issues in the measurement of social inclusion. While it is recognised that the concept is a contested one, for the purposes of the present editorial I offer the World Bank definition: Social Inclusion (SI) refers to the process of improving the terms for individuals and groups to take part in society.
\end{abstract}

\section{Keywords}

concept; indicators; measurement; mental health; social inclusion

\section{Issue}

This editorial is part of the special issue "Indicators and Measurement of Social Inclusion", edited by Professor Peter Huxley (Bangor University, UK).

(C) 2015 by the author; licensee Cogitatio (Lisbon, Portugal). This article is licensed under a Creative Commons Attribution 4.0 International License (CC BY).

Social inclusion is a global phenomenon, and this is reflected in the range of papers in this special issue. Three are from Europe, and one each from Australia and Canada. Our own work on the measurement of social inclusion has been conducted in Hong Kong and Singapore (Chan, Evans, Chiu, Huxley, \& Ng, 2014).

The papers in the special issue cover some of the most significant methodological and conceptual issues in the measurement of social inclusion. While it is recognised that the concept is a contested one, for the purposes of the present editorial I offer the World Bank definition: Social Inclusion (SI) refers to the process of improving the terms for individuals and groups to take part in society.

A number of measures of social inclusion have been developed for use in primary research in clinical and intervention studies. Two of such instruments feature in the present volume, the Social Inclusion Scale (Wilson and Secker), and the Support Needs Questionnaire (Davis and Burns). Wilson and Secker originally developed the SIS for an evaluation of an arts projects for people with mental health problems and here they report on a validation exercise conducted with students. Davis and Burns developed the SNQ for the evaluation of mental health recovery services in South London.
Both illustrate the potential for social inclusion measures to inform clinical practice, programme evaluation and outcome measurement.

For both of the reported instruments, aspects of reliability and validity are good, but there is clearly scope for more work on sensitivity to change over time, and potential item redundancy. The same research is also needed in respect of the Social and Communities Opportunities Profile (Huxley et al., 2011) and the Chinese version the SCOPE-C (Chan et al., 2014).

Wilson and Secker point out there is currently no gold standard measure of social inclusion, nor is there exact agreement upon the indicators of social inclusion. It is, nevertheless, interesting that all the papers and work in Asia come to similar general conclusions about the nature of the indicators of inclusion, which is that they encompass (as Cok Vrooman and colleagues put it) , material well-being, social participation, rights and normative integration. Gingrich and Lightman also point to the material, social and relational aspects of inclusion. A number of studies of normative integration make use of national census or national survey data to conduct secondary analyses of factors associated with social inclusion, as is the case with the contributions of Gingrich and Lightman, and Miranti and Yu. The use of 
census and other national surveys to provide questions to populate social inclusion domains means that research samples can be described and compared to national results using the same questions.

Although, as Byrne (2005) has suggested social inclusion happens in a particular time and place, the present volume and work in Asia, shows that there is a broad measure of agreement on domain content around the world. The life domains reflect the wider conceptualisation referred to in the last paragraph: employment, finance, leisure, social activity and participation, family and friends, housing and living situation, and safety.

The questions designed to elicit inclusion status within domains need to be thought of as being context specific. For instance, in the UK, two-car ownership has been used as a proxy for material well-being, as it is closely related to social class. In Hong-Kong however, this question has almost no variance, and an alternative is required.

The contributions to this volume (eg, Cok Vrooman et al., and Miranti and Yu) confirm that a failure to promote social inclusion in young people may scar them for life, and better health and greater material well-being, and employment are all predictors of inclusion. With increasing international mobility and migration issues, the resolution of social inclusion problems will be of urgent importance in the coming years. In the same way that the concept of "quality of life" has entered into the collective consciousness, so the term social inclusion can be expected to become more accept- ed and widespread, in social policy and academia. We hope that the reader finds food for further thought (and research) in these articles on measurement and indicators.

\section{Acknowledgments}

Thanks to the Journal editors for inviting me to edit this special edition, and to the contributors.

\section{Conflict of Interests}

The author declares no conflict of interests.

\section{References}

Byrne, D. (2005). Social exclusion (2 ${ }^{\text {nd }}$ edition). UK: McGraw-Hill Education.

Chan, K., Evans, S., Chiu, M., Huxley, P., \& Ng, Y. L. (2014). Relationship between health, experience of discrimination, and social inclusion among mental health service users in Hong Kong. Social Indicators Research. doi:10.1007/s11205-014-0780-x

Huxley, P., Evans, S., Madge, S., Webber, M., Burchardt, T., McDaid, D., \& Knapp, M. (2011). Development of a social inclusion index to capture subjective and objective life domains (phase II) (Report No.: 06/91/16). UK: National Institute of Health Research, Health Technology Assessment Programme.

\section{About the Author}

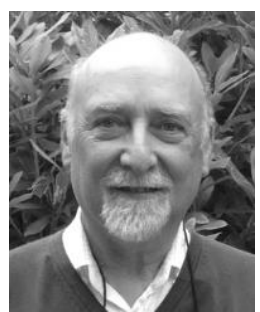

Dr. Peter Huxley

Professor Huxley has published over 160 peer reviewed articles and eleven books. He was the first Professor of Psychiatric Social Work in the UK and the first social worker to be the Head of a School of Psychiatry, both at Manchester University. He was the first Professor of Social Work at the Institute of Psychiatry in London and the first Director of the Department of Health funded Social Care Workforce Research Unit. He has developed three quality of life measures, two social inclusion measures and measures of service satisfaction, and social capital. 